\title{
PREVENCIÓN DE AHOGAMIENTOS: QUE SE TRATE DE NOSOTROS
}

\author{
Ana Ortiz olivar \\ Secretaría de Educación física, Deportes y Recreación. Intendencia de Montevideo (Uruguay
}

\section{OPEN ACCESS}

Correspondencia:

Ana Ortiz Oliva

Secretaría de Educación física, Deportes y

Recreación

Intendencia de Montevideo

Estadio Centenario, Tribuna Colombes $\mathrm{s} / \mathrm{n}$ Montevideo (Uruguay) ana.ortiz@imm.gub.uy

Citación:

Ortiz, A. (2019). Prevención de ahogameintos. Que se trate de nosotros.

RIAA. Revista de Investigación en Actividades Acuáticas, 3(6), 33-34. https://doi.org/10.21134/riaa.v3i6.1831

@creative

Creative Commons Licens Esta obra está bajo una licencia de Creative Commons Reconocimiento-

NoComercial-Compartir-Igual 4.0 Internacional
"El dolor por la muerte de un niño es inconmensurable" (Unicef, 2012) Así abre en su prefacio, el último Informe mundial de prevención de lesiones en los niños. El ahogamiento, se define como el proceso de experimentar dificultades respiratorias por inmersión o sumersión en un líquido (Van Beeck; Branche; Szpilman; Modell y Bierens, 2005). Sus consecuencias pueden resultar en muerte, morbilidad o no morbilidad. Puede suceder en variedad de climas o escenarios geográficos, como la playa, el río, piscinas, inundaciones o el hogar y en diversas actividades, sean estas recreativas, la vida doméstica, laborales o deportivas (Stallman, Moran, Quan, y Langendorfer, 2017). El Informe mundial de prevención de ahogamientos reporta como factores de riesgo, a la pobreza, la niñez, la adolescencia, el fácil acceso a espejos de agua, la falta de supervisión adecuada, de habilidades acuáticas y de sensibilización respecto a la seguridad en el agua y a los comportamientos seguros (World Health Organization, 2014).

Desde la evidencia científica, Unicef plantea que "la enseñanza de la natación mejora la aptitud de nadar, pero no hay pruebas concluyentes de que esta aptitud proteja del riesgo de ahogamiento" (Unicef, 2012. p. 76). Sería necesario que esta habilidad se acompañe de otros conocimientos sobre riesgos, como las rocas, las corrientes de retorno y sobre comportamientos seguros, especialmente en aguas abiertas. De esta forma, algunas de las principales medidas de prevención sugeridas son la supervisión adecuada, constante y capaz de los más pequeños; el conocimiento de los propios límites, la capacidad de reconocimiento de riesgos y en adolescentes la capacidad de resistir la presión del grupo de pares para participar en actividades para las que no se tienen las competencias necesarias (Unicef, 2012). Enseñar a nadar con seguridad asociado a conocimientos de seguridad acuática y habilidades de rescate seguro, son parte de las principales medidas de prevención recomendadas por la Organización Mundial de la Salud (WHO, 2014).

¿Es posible desde la educación acuática tender puentes hacia la prevención? Desde dichos informes se abre una múltiple necesidad. La primera implica pensar acerca de qué habilidades, actitudes y conocimientos son los saberes necesarios. En segundo lugar, pensar en una educación acuática cuyos sujetos no sean únicamente los saberes sino también una forma de vincularse con el medio. En tercer lugar, pensarnos en nuestra cultura, en las características geográficas de nuestro contexto, de nuestros alumnos, en los usos y goces que damos a los espacios acuáticos disponibles. Por último, de haber datos, adaptar y crear intervenciones que aborden las causas más frecuentes de esta lesión y jerarquicen como objetivos a las poblaciones más vulnerables.

Abordemos la primera cuestión en relación a la prevención. En virtud de ello es necesario integrar un concepto más abarcativo e integral que trascienda como sujeto de la producción de conocimientos a las meras habilidades acuáticas, sean básicas o técnicas. El concepto de competencia acuática ha contribuido en gran medida a poder hacerlo. En relación a la prevención, el Dr. Kevin Moran, investigador referente en el área, define a la competencia acuática como la suma de todas las habilidades acuáticas personales que ayudan a prevenir el ahogamiento, así como la asociación de conocimientos sobre seguridad acuática, actitudes y conductas que facilitan la seguridad en, sobre y alrededor del agua (citado por Stallman, Moran, Quan y Langendorfer, 2017). Tomaremos como ejemplo a las principales habilidades de supervivencia, flotar y nadar. Abordar las competencias de flotación implicaría construir conocimientos acerca de cómo flotar mejor, cómo hacerlo con ropa en aguas cálidas o frías, cómo hacerlo cuando no se sabe cuánto va a durar la situación de riesgo y cómo poder pedir ayuda en estos escenarios. Si pensamos en nadar como competencias propulsivas, reconocer qué distancia podríamos nadar con autonomía, qué podríamos hacer si nos cansamos y no hay de donde sostenerse, cómo deberíamos actuar si estamos en una corriente de retorno, cómo podríamos resolver una caída inesperada con ropa en aguas cálidas o frías. Este abordaje requiere pensar creativamente y estudiar desde la evidencia científica qué posibles múltiples soluciones necesitaríamos para nuestros contextos. 
Prevenir lesiones en el agua involucra un conocimiento crítico del medioambiente. Esta perspectiva implica una mirada amplia relacionada con la cultura, salir de la piscina, construir situaciones creadoras de saberes que puedan en cierta medida simular la transferencia de las competencias acuáticas a su posible comportamiento en diversos escenarios de la propia geografía. Aquí entra en juego el vínculo con el medio como sujeto de la educación también. Cuando nos referimos a construir o crear conocimientos, nos posicionamos en una pedagogía crítica (Freire, 1997), en estilos de enseñanza basados en experiencias de desafío, de interacción y de creatividad. De esta forma, capitalizar la duda, la curiosidad y el conflicto con lo que damos por dado, como momentos de creación del saber. A través del desarrollo de la criticidad, contribuimos a formar personas críticas (Freire, 1997). A través de la interacción, contribuimos a ampliar los aprendizajes y a la convivencia entre pares con diferentes competencias y experiencias. A través de las emociones positivas, desarrolladas por las experiencias de clase, favorecemos la toma de decisiones. La emoción es importante para pensar con claridad y para la toma de decisiones acertadas (Nicoliello, 2010, p. 99). Apostemos y animémonos a la creación colectiva del conocimiento con nuestros alumnos, que parta de su expresión, de su cultura, como celebración de nuestro encuentro en el agua.

Por último, compartimos nuestra experiencia uruguaya, donde guardavidas y profesores de educación física hemos desarrollado Escuelas de mar, desde hace 20 años. Tanto en la costa atlántica como del Río de la Plata, abordando a las competencias preventivas desde la experiencia de jugar con el propio cuerpo en el mar y las olas, desde la enseñanza del surfing, el canotaje y el salvamento acuático deportivo, incorporando saberes para su disfrute con seguridad. Desde hace 10 años desarrollamos programas Guardavidas Junior en escuelas públicas, basados en experiencias sobre competencias preventivas de nuestro contexto. Desde el año 2017, conformamos una Mesa Interinstitucional para la Seguridad Acuática, donde diversos actores como la Armada Nacional, la Sociedad Uruguaya de Pediatría, Guardavidas y Profesores de Educación Física, Secretarías de Deporte departamental y nacional, Ministerio de Salud, entre otros, abordamos al ahogamiento de forma multisectorial (Ministerio de salud, 2018). Hoy, estamos reflexionando juntos y elaborando una Plan Nacional de Seguridad Acuática desde el cual investigar, promover legislación, asesorar, crear y desarrollar intervenciones propias.

Desde esta editorial, buscamos compartir elementos que nos inviten a reflexionar sobre nosotros, resignificar la propia voz y la de otras experiencias para ponerlas en diálogo. Un diálogo que sea palabra y acción a la vez. Dialoguemos con nuestros alumnos, las familias, colegas, la comunidad y con otros campos de conocimiento. La seguridad acuática se construye dialogando. Hoy tenemos a la prevención en nuestras manos. Hoy podemos pensar creativamente en una educación acuática que no solo trate de saberes, sino que se trate de nosotros. ¡Hagámoslo!

\section{Referencias}

Beeck, E. F. van, Branche, C. M., Szpilman, D., Modell, J. H., \& Bierens, J. J. L. M. (2005). A new definition of drowning: towards documentation and prevention of a global public health problem [Una nueva definición de ahogamientos: hacia la documentación y prevención de un problema de salud global]/ E. F. van Beeck ... [et al.]. The International Journal of Public Health, 83(11), 853-856.

Freire, P. (1997). El grito manso. Argentina: Siglo veintiuno editores.

Ministerio de Salud (2018). Mesa Interinstitucional de Seguridad Acuática. Disponible en: https://www.gub.uy/ministerio-salud-publica/comunicacion/noticias/mesa-interinstitucional-deseguridad-acuatica

Nicoliello, M. (2010). La inteligencia emocional histórica en el aula y otros contextos. Montevideo: Editorial Planeta.

Szpilman, D., Bierens, J., Handley, A., J., \& Orlowski, J. (2012). Drowning. Current concepts [Ahogamientos. Conceptos actuales]. New England Journal of Medicine, 366, 2102-2110.

Stallman, R. K., Moran, K., Quan, L., \& Langendorfer, S. (2017). "From Swimming Skill to Water Competence": Towards a More Inclusive Drowning Prevention Future [“Desde la Habilidad de Nadar a la Competencia Acuática": Hacia un Futuro más Inclusivo de la Prevención de Ahogamientos. International Journal of Aquatic Research and Education, 10(2), artículo 3.

UNICEF (2012). Informe mundial de prevención de lesiones en los niños. Organización Mundial de la Salud, United Nations International Children's Emergency Fund.

World Health Organization (2014). Global Report on Drowning: Preventing a leading killer [Informe Global de Ahogamientos: Previniendo un importante asesino]. WHO. Recuperado de:

https://www.who.int/violence_injury_prevention/global_report_drowning/en/ 